\title{
DOSSIER ENSAYOS SOBRE LA PANDEMIA
}

La pandemia COVID-19 ha cambiado en muchos aspectos nuestras vidas y relaciones. En los primeros meses todo fue novedoso e incertidumbre. Todos los países tuvieron una afectación relevante. Los niveles de contagio se aceleraron, el colapso de los sistemas de salud no discriminó el nivel de desarrollo de los países y la crisis socioeconómica ha sido un hito, que dejará profundas cicatrices y desafíos múltiples en el mundo.

Este dossier recoge reflexiones, a manera de ensayo, de importantes investigadores que nos compartieron, entre junio y julio del año 2020 en la Universidad de Valparaíso, una serie de perspectivas sobre los hechos y contextos que se nos presentaban con motivo de la pandemia. En los seminarios online (webinar), hubo espacio para hacer una retrospectiva de nuestras trayectorias económicas, políticas, sociales y culturales.

Cada espacio de conversación nos llevó a realizar numerosas interrogantes, que eran de pocas respuestas con certezas. Discutimos sobre fuerza de trabajo, salarios, renta básica universal, empresa/ empresarios, Estado y política pública, globalización, pobreza, trabajo doméstico, migración, mujeres y vulnerabilidad y sobre todo cómo sería nuestro planeta en la postpandemia.

Nos pareció importante sistematizar las presentaciones, para ampliar su conocimiento y fijarlo como un registro intelectual sincrónico de cómo pensamos la economía, la sociedad, la cultura, la convivencia y las nuevas formas de solución a los desafíos locales y globales, toda vez que tendremos una postpandemia más prolongada de los previsto.

Agradezco, como director/editor de la revista Perfiles Económicos, la generosidad y confianza que depositaron todos los autores en nuestra publicación, para editar sus presentaciones orales y posteriormente hacer la revisión y corrección de estas. Vaya mi reconocimiento para Daniel Raventós (Barcelona), Ernesto Ottone (Santiago, Chile), María Dolores Lorenzo (ciudad de México), Andrea Lluch (Buenos Aires) y Bernardita Escobar (Santiago, Chile).

Patricio Herrera González

Director/Editor 